\title{
Application of receiver operating characteristic curve in the assessment of the value of body mass index, waist circumference and percentage of body fat in the Diagnosis of Polycystic Ovary Syndrome in childbearing women
}

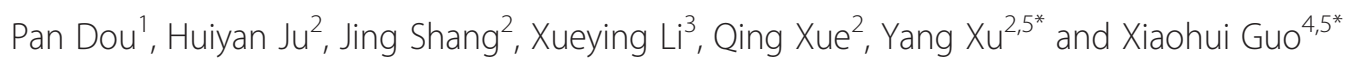

\begin{abstract}
Background: There are various parameters to analyze obesity, however, no standard reference to predict, screen or diagnose PCOS with various obesity parameters has been established, and the accuracy of these parameters still needs to be studied.This study was to use the receiver operating characteristic (ROC) curve to explore the different values of three obesity parameters, body mass index (BMI), waist circumference (WC) and percentage of body fat (PBF) in the diagnosis of polycystic ovary syndrome (PCOS) in Chinese childbearing women.
\end{abstract}

Methods: Three hundred patients who were diagnosed with PCOS at Center of Reproductive Medicine and Genetics of Peking University First Hospital were enrolled in this study, and 110 healthy age-matched women were enrolled as controls. The characteristics of BMI, WC and PBF in PCOS patients were analyzed.

Results: Compared with the control group, all the three obesity parameters were significantly increased in PCOS group. In terms of ROC area under the curve, WC > PBF > BMI, and they were all significantly different from those of the control. At a cut-off point of $80.5 \mathrm{~cm}$, WC has a sensitivity of $73.6 \%$ and a specificity of $85 \%$ in diagnosis of PCOS; At a cut-off point of $29 \%$, PBF has a sensitivity of $88.2 \%$ and a specificity of $57.7 \%$ in diagnosis of PCOS; and at a cut-off point of $26.6 \mathrm{~kg} / \mathrm{m}^{2}$, BMl has a sensitivity of $54.5 \%$ and a specificity of $98 \%$ in diagnosis of PCOS.

Conclusion: WC, BMI and PBF are valuable in screening and diagnosis of PCOS in Chinese childbearing women. PBF can be used to screen PCOS as it has a better sensitivity, while BMI can be used in the diagnosis of PCOS as it has a better specificity.

Keywords: Childbearing age, Polycystic ovary syndrome, Obesity, Body mass index, Waist circumference, percentage of body fat, Receiver operating characteristic, Area under the curve

Abbreviations: $\mathrm{ROC}$, the receiver operating characteristic; BMI, body mass index; WC, waist circumference; PBF, percentage of body fat; PCOS, polycystic ovary syndrome; LH, luteinizing hormone; ASRM, the American Society for Reproductive Medicine; SHBG, sex hormone-binding globulin; WHO, World Health Organization; IDF, the International Diabetes Federation

\footnotetext{
*Correspondence: xuyangm@126.com; guoxh@medmail.com.cn

${ }^{2}$ Center of Reproduction and Genetics, Peking University First Hospital, Beijing, China

${ }^{4}$ Department of Endocrinology, Peking University First Hospital, Beijing, China

Full list of author information is available at the end of the article
} 


\section{Background}

Polycystic ovary syndrome (PCOS) was first reported by Stein and Leventhal [1] in 1935, so it is also called SteinLeventhal syndrome. It is the most common female endocrine and metabolic disorder, and its incidence rate is about $5.6 \%$ among women aged 19-45 years old in China [2]. PCOS is a complex disease with high clinical heterogeneity, excess androgen production and elevated serum luteinizing hormone $(\mathrm{LH})$ are its serological features. It is a major cause of infertility in women. Studies from different countries have shown that the comorbidity rate of obesity in patients with PCOS was 30-70\% [3, 4]. The reproductive, endocrinological and metabolic disorders (except hirsutism) in obese PCOS patients are more severe than non-obese patients, and the long-term risk of the incidence of metabolic syndrome, type 2 diabetes mellitus (DM), cardiovascular disease (CVD) as well as breast cancer, endometrial cancer and other complications was also increased exponentially [5]. There are various parameters to analyze obesity, however, no standard reference to predict, screen or diagnose PCOS with various obesity parameters has been established, and the accuracy of these parameters still needs to be studied. This study was designed based on the Rotterdam PCOS consensus criteria, to explore the accuracy and best cut-off points of three obesity parameter, i.e., body mass index (BMI), waist circumference (WC) and percentage of body fat (PBF), in PCOS diagnosis, as well as to compare their sensitivity and specificity to provide basis for rational application of obesity parameters in prediction, screen and diagnosis of PCOS among high-risk populations.

\section{Methods}

\section{Study subjects}

Three hundred study subjects who were diagnosed with PCOS at Reproduction and Genetic Center of Peking University First Hospital from June 2015 to January 2016 were selected. Patients were did not take any hormone medication within the past 3 months. 110 healthy women of childbearing age who have normal menstruation period and biphasic basal body temperature were selected as normal control. The ages of the two groups were matched to each other. This study was approved by the Ethics Committee of China Registered Clinical Trial and all the study subject have signed informed consent to voluntarily participate the study.

\section{PCOS diagnostic criteria}

Based on the American Society for Reproductive Medicine (ASRM) Rotterdam Revised Diagnostic Criteria, a patient can be with diagnosed as PCOS if two of the following three criteria are met: (1) no ovulation or irregular ovulation; (2) clinical (such as hirsutism, acne) or biochemical evidence associated with elevated androgen levels; (3) enlarged ovaries, each side has 12 or more small follicles with a diameter of at least $2 \sim 9 \mathrm{~mm}$; plus exclusion of hyperlactatemia and other metabolic diseases that produce high-level of androgen such as Cushing's syndrome, congenital adrenal hyperplasia, ovarian or adrenal tumors.

\section{Anthropometric measurements}

Measurements were carried out in the hospital's outpatient clinic, performed by the same observer in accordance with the provisions of WHO. For measurement of height (m), the examinee was required to be barefoot, the rear point of the feet, hip and the rear point of head were on the same vertical line, the measurement value was approximated to the nearest $0.5 \mathrm{~cm}$; for measurement of body weight $(\mathrm{kg})$, electronic scale was used, and the examinee was required to be fasted overnight and urine and stool were emptied, only underwear was allowed, the measurement values was approximated to the nearest $100 \mathrm{~g}$, BMI was calculated with the formula: weight $(\mathrm{kg}) /(\text { height })^{2}\left(\mathrm{~m}^{2}\right)$; for measurement of waist circumference, the examinee was required to stand upright with two feet apart $25 \sim 30 \mathrm{~cm}$, so that the weight is evenly distributed on both legs, the waist circumference was measured in a horizontal level through the midpoint that links the iliac crest and the lower margin of the 12th rib (the measurement tape was placed close to the skin, but cannot repress the soft tissue), the measurement values was approximated to the nearest $1 \mathrm{~mm}$.

\section{Body composition measurement}

The body composition of the two groups was measured using bioelectrical impedance body composition analyzer (Multi-frequency bioelectrical impedance analyzer NQAPI). On the test day, the examinee was asked to minimize eating and drinking, no tense activity was allowed within $6 \mathrm{~h}$ before the test to avoid its affection on body composition measurements. During measurement, the examinee was asked to take off socks, standing on the test bench with the body relaxed, with both feet on the foot electrodes and both hands holding firmly on the hand electrodes, then basal metabolic rate, total water, the amount of non-fat tissue, muscle mass, body fat mass, and percentage of body fat (PBF) were measured.

\section{Statistical analysis}

SAS 9.3 software was used in statistical analysis. 1). Measurement data were shown as $\bar{x} \pm s$, independent sample $t$ test or Wilcoxon test was used to compare difference between the two groups, $\mathrm{P}<0.05$ was considered statistically significant; 2). Receiver operating characteristic curve (ROC curve) was drawn using Mann-Whitney method, and area under the ROC curve (area under curve, AUC) and Somers' D were used to determine the overall accuracy of each predictor (area under the curve $\geq 0.5$ was considered to have diagnostic value, 
the larger the area, the larger the value); the optimal cut-off points for BMI, WC, PBF to predict PCOS was determined according to Youden index maximum points; 3). The cut-off point where the sensitivity reaches $90 \%$ was determined as the reference standard for screening PCOS with BMI, WC and PBF; 4). The cut-off point where the specificity reaches $90 \%$ was determined as the reference standard for diagnosis of PCOS with BMI, WC and PBF.

\section{Results}

\section{Comparison of Age, BMI, WC and PBF between the two groups}

Comparison was performed using independent samples $t$ test or Wilcoxon test. The ages of the PCOS group were between 16 to 40 years with mean $28.55 \pm 4.27$ years; the ages of control group were between 23 to 38 years with mean $28.53 \pm 3.26$ years. There was no significant difference between the two groups (Table 1). As shown in Table 1 and Fig. 1, compared with the healthy control group, all three parameters, WC $(89.67 \pm 13.93$ vs $75 \pm$ 7.11), PBF (34.69 \pm 5.72 vs $29.12 \pm 5.05)$ and BMI (27.51 \pm 5.37 vs $22.55 \pm 2.9)$ in PCOS group were significantly increased ( $P=0.000$ for all comparisons), indicating that these three parameters are valuable in facilitating the screening or diagnosis of PCOS.

\section{ROC curves of BMI, WC and PBF for diagnosing PCOS}

The Rotterdam criteria was used as the gold standard when to evaluate the accuracy of BMI, WC and PBF to predict PCOS. Figure 2 is the ROC curve of the three obesity parameters for diagnosing PCOS, Table 2 is the area under the ROC curve of the three parameters for diagnosing PCOS. The results in Table 2 show that in general, the mean AUC for WC to diagnose PCOS is 0.814 with a standard error of $0.029(P<0.001$ compared with 0.5 which was set as a standard comparison for
AUC, please refer to the Statistical Analysis section); the mean AUC for PBF to diagnose PCOS is 0.789 with a standard error of $0.025(P<0.001$ compared with 0.5$)$; the mean AUC for BMI to diagnose PCOS is 0.782 with a standard error of $0.028(P<0.001$ compared with 0.5$)$. Each of the two groups was further divided into three subgroups according to age: <26 y/o group, 26-31 y/o group and $>31 \mathrm{y} / \mathrm{o}$ group, and the data were further analyzed according to age groups. It was shown that the AUCs of all the subgroups of the three obesity parameters were all significantly larger than $0.5(P<0.001)$. Comparisons were also performed among the three parameters and there is no significant difference between any of them, meaning that there is no better predictor for PCOS among them.

The cut-off points and other features of the three obesity parameters to diagnose PCOS

ROC curves as mentioned above was used to select the best cut-off points of each of the three parameters to diagnose PCOS. As mentioned in the Statistical Analysis section, the best cut-off points for each of the three parameters to diagnose PCOS was determined based on the maximum point of Youden index. In general, the best cut-off point for WC to diagnose PCOS is $80.5 \mathrm{~cm}$, and at that point, its sensitivity to diagnose PCOS is $73.6 \%$, and specificity is $85.0 \%$; the best cut-off point for PBF to diagnose PCOS is $29 \%$, and at that point, its sensitivity to diagnose PCOS is $88.2 \%$, and specificity is $57.7 \%$; the best cut-off point for BMI to diagnose PCOS is $26.6 \mathrm{~kg} / \mathrm{m}^{2}$, and at that point, its sensitivity to diagnose PCOS is $54.5 \%$, specificity is $98.0 \%$. The results are shown in Table 3. In the age subgroups, the trend is similar: it seems that PBF has a better sensitivity and can be used to screen PCOS, while BMI can be used in the diagnosis of PCOS as it has a better specificity. The only

Table 1 Comparison of age, WC, PBF and BMI between control and PCOS groups

\begin{tabular}{llll}
\hline variables & Statistical parameters & Control group $(n=300)$ & PCOS group $(n=110)$ \\
\hline Age $(\mathrm{y} / \mathrm{o})$ & $\bar{x} \pm s$ & $28.53 \pm 3.26$ & $28.55 \pm 4.27$ \\
& Median & $28.5(27,30)$ & $28(26,31)$ \\
& Range (Max, Min) & $15(23,38)$ & $24(16,40)$ \\
WC $(\mathrm{cm})$ & $\bar{x} \pm s$ & $75 \pm 7.11$ & $89.67 \pm 13.93$ \\
& Median & $75(67,79)$ & $89(80,100)$ \\
& Range (Max, Min) & $28(64,92)$ & $60(64,124)$ \\
PBF (\%) & $\bar{x} \pm s$ & $29.12 \pm 5.05$ & $34.69 \pm 5.72$ \\
& Median & $28.58(26,32)$ & $34.19(30.98,38.27)$ \\
& Range (Max, Min) & $40.1(6.55,46.65)$ & $31.32(16.11,47.43)$ \\
BMI $\left(\mathrm{kg} / \mathrm{m}^{2}\right)$ & $\bar{x} \pm s$ & $22.55 \pm 2.9$ & $27.51 \pm 5.37$ \\
& Median & $22.81(20.39,24.01)$ & $27.26(23.36,31.61)$ \\
& Range (Max, Min) & $16.92(17.46,34.37)$ & $26.77(17.46,44.23)$ \\
\hline
\end{tabular}



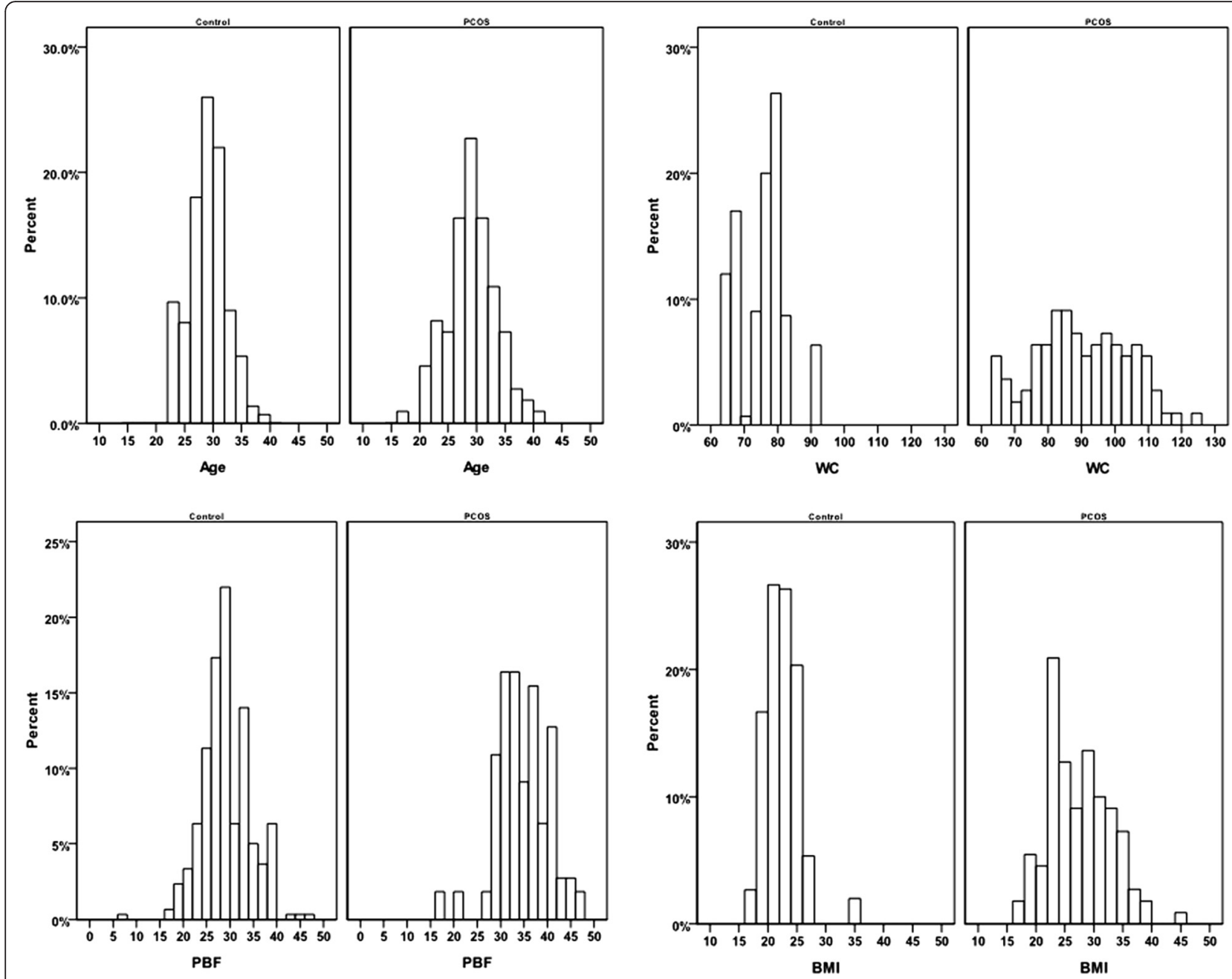

Fig. 1 The percentage histogram of age, WC, PBF and BMI between PCOS and normal control groups

exception is that in age subgroup of older than $31 \mathrm{y} / \mathrm{o}$, WC has a better sensitivity than PBF (81.3\% vs $71.9 \%)$.

\section{Discussion}

Studies from different countries have shown that the incidence rate of obesity in patients with PCOS was $30-70 \%[3,4]$. Obese PCOS patients tend to have more severe endocrinological, reproductive and metabolic disorders (except hirsutism), manifested by increases of total testosterone level, fasting glucose level, fasting insulin level, insulin resistance and lipid lvel, and decrease of sex hormone-binding globulin (SHBG) level [6]. The current view of the main mechanism of PCOS is the accumulation of excessive visceral fat tissue which causes insulin resistance through secretion of factors such as leptin [7], adiponectin, interleukin-6. This was followed by promotion of androgen synthesis by theca cells and inhibition of hepatic synthesis of SHBG, which together lead to increase of free testosterone concentration in the blood, and subsequently exacerbation of hyperandrogenism further [8]. In addition to affecting women's reproductive function and pregnancy outcomes, the risk of metabolic syndrome, type $2 \mathrm{DM}$, CVD and breast cancer, endometrial cancer and other long-term complications in obese PCOS patients are also exponentially increased [5]. The main causes of obesity in PCOS patients are excessive daily intake of carbohydraterich, high-glycemic and high saturated fat diet, and too little exercise [9]. Mild weight loss in overweight or obese PCOS patients (a decrease of 5-10 \%) could lead to decline in serum testosterone levels, also lead to return of normal ovulation cycle, improve pregnancy success rate [10-13] , and improve hormone, glucose and lipid metabolism disorders [14] and decrease the risk for CVD [15]. Therefore, physicians should not only intervene against PCOS' clinical manifestations, but also should encourage weight loss in these PCOS patients to decrease long-term metabolic risk.

There are many parameters in analyzing obesity, among which, BMI, WC and PBF are the most widely used ones, but with different focus: BMI focus on evaluation of human density, WC focus on evaluation of human girth, PBF focus 


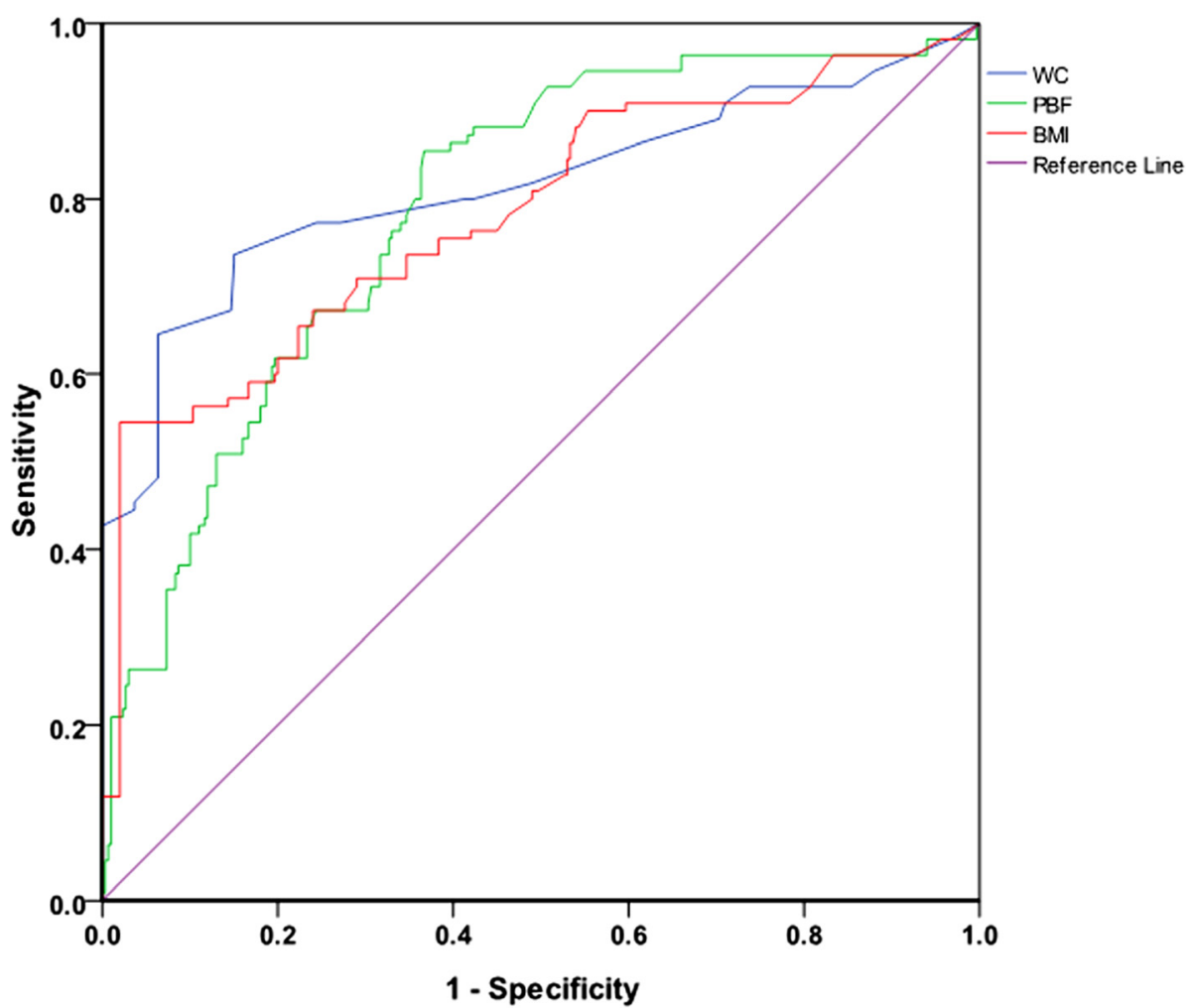

Fig. 2 ROC curve of WC, PBF and BMI for the diagnosis of PCOS

on evaluation of body fat [16]. The accuracy of using these three parameters to predict and diagnose obese PCOS still need to be assessed. In the meantime, due to the difference in race among different countries around the world, there is difference in detection rate of obesity when different cutoff points of obesity parameters were used, therefore, it is necessary to study the cut-off points of BMI, WC and PBF unique to Chinese women of child-bearing age with PCOS. This study was based on the Rotterdam diagnosis criteria for PCOS [17], where we analyzed the BMI, WC and PBF of 300 women ofchild-bearing age with PCOS who visited the Reproduction and Genetic Center in Peking University

Table 2 AUC of ROC of WC, PBF and BMI to diagnose PCOS

\begin{tabular}{|c|c|c|c|c|c|c|c|}
\hline \multirow{2}{*}{$\begin{array}{l}\text { Age } \\
(y / 0)\end{array}$} & \multirow{2}{*}{$\begin{array}{l}\text { Obesity } \\
\text { parameter }\end{array}$} & \multirow[t]{2}{*}{$A U C \pm S E$} & \multicolumn{2}{|c|}{$95 \% \mathrm{Cl}$ of $\mathrm{AUC}$} & \multirow[t]{2}{*}{ Somers' D } & \multirow[t]{2}{*}{$P^{a}$} & \multirow[t]{2}{*}{$P$} \\
\hline & & & Lower limit & Upper limit & & & \\
\hline \multirow[t]{3}{*}{$\overline{<26}$} & $W C(\mathrm{~cm})$ & $0.798 \pm 0.068$ & 0.665 & 0.930 & 0.596 & $<0.001$ & $0.558^{b}$ \\
\hline & PBF (\%) & $0.769 \pm 0.060$ & 0.650 & 0.887 & 0.537 & $<0.001$ & $0.526^{c}$ \\
\hline & $\mathrm{BMI}\left(\mathrm{kg} / \mathrm{m}^{2}\right)$ & $0.817 \pm 0.059$ & 0.701 & 0.933 & 0.634 & $<0.001$ & $0.134^{d}$ \\
\hline \multirow[t]{3}{*}{$26-31$} & $W C(\mathrm{~cm})$ & $0.787 \pm 0.0423$ & 0.704 & 0.8700 & 0.574 & $<0.001$ & $0.551^{b}$ \\
\hline & PBF (\%) & $0.765 \pm 0.0361$ & 0.694 & 0.8355 & 0.529 & $<0.001$ & $0.544^{c}$ \\
\hline & $\mathrm{BMI}\left(\mathrm{kg} / \mathrm{m}^{2}\right)$ & $0.768 \pm 0.0403$ & 0.689 & 0.8472 & 0.537 & $<0.001$ & $0.898^{d}$ \\
\hline \multirow[t]{3}{*}{$>31$} & WC (cm) & $0.889 \pm 0.043$ & 0.806 & 0.973 & 0.779 & $<0.001$ & $0.001^{b}$ \\
\hline & PBF (\%) & $0.838 \pm 0.042$ & 0.756 & 0.920 & 0.676 & $<0.001$ & $0.090^{c}$ \\
\hline & BMI $\left(\mathrm{kg} / \mathrm{m}^{2}\right)$ & $0.773 \pm 0.061$ & 0.654 & 0.891 & 0.545 & $<0.001$ & $0.138^{d}$ \\
\hline \multirow[t]{3}{*}{ 合计 } & $W C(\mathrm{~cm})$ & $0.814 \pm 0.029$ & 0.758 & 0.870 & 0.629 & $<0.001$ & $0.100^{b}$ \\
\hline & PBF (\%) & $0.789 \pm 0.025$ & 0.7397 & 0.838 & 0.577 & $<0.001$ & $0.261^{c}$ \\
\hline & $\mathrm{BMI}\left(\mathrm{kg} / \mathrm{m}^{2}\right)$ & $0.782 \pm 0.028$ & 0.7265 & 0.838 & 0.564 & $<0.001$ & $0.724^{d}$ \\
\hline
\end{tabular}

${ }^{\mathrm{a}} \mathrm{AUC}$ compared with 0.5

${ }^{\mathrm{b}}$ compared with BMI

compared with WC

d compared with PBF 
Table 3 Cut-off points and other parameters of WC, PBF and BMI in diagnosis of PCOS

\begin{tabular}{|c|c|c|c|c|c|c|c|}
\hline Age (y/o) & Obesity parameter & Cut-off point & Sensitivity (\%) & Specificity (\%) & Youden index & NPV (\%) & PPV (\%) \\
\hline \multirow[t]{3}{*}{$<26$} & WC (cm) & 93.5 & 56.5 & 100 & 0.565 & 69.7 & 100 \\
\hline & PBF (\%) & 28.3 & 91.3 & 64.2 & 0.555 & 88.1 & 71.8 \\
\hline & $\mathrm{BMI}\left(\mathrm{kg} / \mathrm{m}^{2}\right)$ & 26.6 & 56.5 & 100 & 0.565 & 69.7 & 100 \\
\hline \multirow[t]{3}{*}{$26-31$} & WC $(\mathrm{cm})$ & 80.5 & 69.1 & 84.5 & 0.536 & 73.2 & 81.7 \\
\hline & PBF (\%) & 29.9 & 85.5 & 60.9 & 0.464 & 80.8 & 68.6 \\
\hline & $\mathrm{BMI}\left(\mathrm{kg} / \mathrm{m}^{2}\right)$ & 26.5 & 45.5 & 98.9 & 0.444 & 64.5 & 97.6 \\
\hline \multirow[t]{3}{*}{$>31$} & $W C(\mathrm{~cm})$ & 81.0 & 81.3 & 93.2 & 0.745 & 83.3 & 92.3 \\
\hline & PBF (\%) & 33.0 & 71.9 & 83.6 & 0.555 & 74.8 & 81.4 \\
\hline & $\mathrm{BMI}\left(\mathrm{kg} / \mathrm{m}^{2}\right)$ & 26.6 & 68.8 & 94.5 & 0.633 & 75.2 & 92.6 \\
\hline \multirow[t]{3}{*}{ Total } & $W C(\mathrm{~cm})$ & 80.5 & 73.6 & 85.0 & 0.586 & 76.3 & 83.1 \\
\hline & PBF (\%) & 29.0 & 88.2 & 57.7 & 0.459 & 83.0 & 67.6 \\
\hline & $\mathrm{BMI}\left(\mathrm{kg} / \mathrm{m}^{2}\right)$ & 26.6 & 54.5 & 98.0 & 0.525 & 68.3 & 96.5 \\
\hline
\end{tabular}

First Hospital from June 2015 to January 2016, as well as 110 cases of age-matched healthy women as normal control. We compared the sensitivity and specificity of the three obesity parameters in diagnosing PCOS, trying to provide evidence for reasonable use of obesity parameters in facilitating the diagnosis of PCOS among high risk population.

The results of this study showed that compared with the healthy control group, all three parameters in PCOS group, BMI, WC and PBF were significantly increased, consistent with previous reports [18], indicating the severity of overweight and obesity in patients with PCOS which leads to exacerbation of endocrine and reproductive metabolic disorders [19].

Our results also showed that, the AUC features of the three obesity parameters were greater than 0.5. AUC reflects the sensitivity and specificity of a certain index in general in the diagnosis of diseases, and the overall diagnostic accuracy of this indicator: $0.5<\mathrm{AUC} \leq 0.7$ means a low diagnostic accuracy, $0.7<$ AUC $\leq 0.9$ means medium diagnostic accuracy, $0.9<$ AUC $<1.0$ means a high diagnostic accuracy [20]. This study demonstrated that these three parameters are all valuable for predicting obesity PCOS, and there was no significant difference among them. Previous studies show that, WC is superior in the accuracy of BMI and other parameters in predicting metabolic syndrome in China [21, 22], metabolic syndrome in PCOS patients in South Korea [23] and Brazil [24]. The reason, mainly is that obesity and overweight are two different concepts. BMI represents body mass and represents a proportional relationship between weight and height, and it cannot reflect the body fat content [25-28], and therefore it is not appropriate to use BMI alone to assess the degree of obesity. WC is an indicator of central obesity and central obesity is not correlated with human mass index, it mainly refers to the accumulation of visceral fat, thus it is a better predictor of risk of metabolic syndrome and cardiovascular disease [29], and WC is the simplest method of human body measurement. Results of this study suggest that at the time of the census of PCOS among childbearing women, it is recommended that the first choice is WC measurement since it is simple and has equal value in diagnosing PCOS.

Based on bioelectrical impedance principle, body composition analyzer can measure content of water in human body, as well as calculate PBF. It is an accurate, noninvasive and simple method to measure of the content and the proportion of human body fat [30]. Previous studies have shown that BMI showed high specificity and low sensitivity in the diagnosis of obesity, pointing out that BMI missed almost half of the obese population diagnosed by PBF [31-33]. Recent studies have shown that even with normal-weight, high PBF was also associated with insulin resistance [34], PBF is a better indicator to predict obesity [35], so more and more scholars began to study the value of measurement of body composition in obesity diagnosis [36-40]. The results of this study showed the AUC of PBF is not significantly different from the other two parameters, not consistent with previous findings [41]. Nevertheless, this study suggests that in the future, on the basis of PCOS sample, we can further dig into the value of body fat percentage measured using bioelectrical impedance method in the diagnosis of PCOS.

World Health Organization (WHO) [42] and the International Diabetes Federation (IDF) [43] have determined the cut-off point of BMI and WC in diagnosing obesity according to differences in the ethnic, race and morphology: For Chinese adult, $24 \mathrm{~kg} / \mathrm{m}^{2} \leq \mathrm{BMI}<28 \mathrm{~kg} / \mathrm{m}^{2}$ is defined as overweight, the $B M I \geq 28 \mathrm{~kg} / \mathrm{m}^{2}$ is defined as obese; or female waist $\geq 80 \mathrm{~cm}$ is defined as overweight or central obesity; The normal range value of female PBF is $23 \pm 5 \%$ and $\mathrm{PBF} \geq 30 \%$ is defined as obese. Korean studies 
[23] showed that WC $80 \mathrm{~cm}$ was the best cut-off point for the best prediction of PCOS in Korean women; Brazilian studies [24] show WC $95 \mathrm{~cm}$ was the best cut-off point for the best prediction of PCOS in Brazilian women. The results of this study confirmed that, BMI $26.6 \mathrm{~kg} / \mathrm{m}^{2}$, WC $80.5 \mathrm{~cm}$ and PBF $29 \%$, were the best cut-off point for diagnosing PCOS. The results of this study is similar to the studies with South Korea, which may be related to ethnic characteristics.

The results of this study also showed that, the three obesity parameters have different sensitivity and specificity. For example, whether in general or in age subgroups, BMI always has the best specificity among the three. While with only one exception in one age subgroup, PBF always has the best sensitivity among the three. These results indicate that, to screen for high-risk PCOS patients in Chinese women of reproductive age, PBF is the first choice as it is more sensitive, except in patients over $31 \mathrm{y} / \mathrm{o}$, WC can be used as an alternative. So the cut-off point of PBF at $29 \%$ can be used as reference standard for epidemiological investigation and preliminary screening of PCOS in the community, then the gold standard of Rotterdam criteria was used for confirmatory diagnosis. In this case, not only the risk factor of PCOS can be prevented earlier, but also avoid causing excessive pressure to the public, it can also adapt to the manpower burden in disease prevention and control, is a reasonable strategy in saving health resources.

While in diagnosing PCOS, BMI has better value as it is more specific. So the cut-off point of BMI at $26.6 \mathrm{~kg} / \mathrm{m}^{2}$ can be used to facilitate the diagnosis of PCOS as it has a specificity of $98 \%$. It can be used as a relatively reliable diagnosis reference for PCOS when limited by equipment or economic situation, i.e., no ultrasound or sex hormones test available.

One disadvantage of this study is that the study subjects enrolled in this study were all from northern China, in the future, we still need to further expand the sample size, to summarize population data from multiple regions in China, and to establish a more accurate cut-off points in the prediction, screening and diagnosis of PCOS, as well as to administer weight loss treatment in obese PCOS patients to prevent long-term complications.

\section{Conclusion}

To summarize, endocrine, reproductive and metabolic disorders are more severe in obese PCOS patients. BMI, $\mathrm{WC}$ and PBF are three important parameters to measure obesity. This study shows that patients with PCOS have serious overweight or obesity problems. WC, PBF and BMI are valuable in screening or diagnosing PCOS. PBF has a better sensitivity and can be used to screen PCOS, while BMI can be used in the diagnosis of PCOS as it has a better specificity.

\section{Acknowledgement}

Not applicable.

\section{Funding}

The study was supported by the International Science \& Technology Cooperation Program of China (2013DFA30910) and Research Foundation of Peking University First Hospital(2015QN021)

Availability of data and materials

Not applicable.

\section{Authors' contributions}

$Y X, X G$ and PD mainly participated in literature search, study design, writing and critical revision. HJ, JS, XL, QX mainly participated in data collection, data analysis and data interpretation. All authors read and approved the final manuscript.

\section{Competing interests}

The authors declare that there is no conflict of interest.

Consent for publication

Not applicable.

Ethics approval and consent to participate

This study was approved by the Ethics Committee of China Registered Clinical Trial and all the study subject have signed informed consent to voluntarily participate the study.

\section{Author details}

'Department of Clinical Nutrition, Peking University First Hospital, Beijing, China. ${ }^{2}$ Center of Reproduction and Genetics, Peking University First Hospital, Beijing, China. ${ }^{3}$ Department of Biostatistics, Peking University First Hospital, Beijing, China. ${ }^{4}$ Department of Endocrinology, Peking University First Hospital, Beijing, China. ${ }^{5}$ No.7, Xishiku Road, Xicheng District, Beijing 100034 , People's Republic of China.

Received: 27 June 2016 Accepted: 11 August 2016

Published online: 24 August 2016

\section{References}

1. Stein, Irving F, Leventhal, and Michael L. Amenorrhea associated with bilateral polycystic ovaries. 1935. DOl: http://dx.doi.org/10.1016/S00029378(15)30642-6.

2. Li R, Zhang $Q$, Yang $D$, et al. Prevalence of polycystic ovary syndrome in women in China: a large community-based study. Hum Reprod. 2013;28: 2562-9. doi:10.1093/humrep/det262.

3. Azziz R, Woods KS, Reyna R, Key TJ, Knochenhauer ES, Yildiz BO. The prevalence and features of the polycystic ovary syndrome in an unselected population. J Clin Endocrinol Metab. 2004;89:2745-9. doi:10.1210/jc.2003-032046.

4. Ehrmann DA. Polycystic ovary syndrome. N Eng J Med. 2005;352:1223-36. doi:10.1056/NEJMra041536.

5. Martínezbermejo E, Luqueramírez M, Escobarmorreale HF. Obesity and the polycystic ovary syndrome. Minerva Endocrinol. 2007;32:129-40.

6. Lim SS, Norman RJ, Davies MJ, Moran LJ. The effect of obesity on polycystic ovary syndrome: a systematic review and meta-analysis. Obes Rev. 2013;14: 95-109. doi:10.1111/j.1467-789X.2012.01053.x.

7. Jalilian N, Haghnazari L, Rasolinia S. Leptin and body mass index in polycystic ovary syndrome. Indian J Endocrinol Metab. 2016;20:324-8. doi:10.4103/2230-8210.180005.

8. Ehrmann DA, Liljenquist DR, Kasza $K$, et al. Prevalence and predictors of the metabolic syndrome in women with polycystic ovary syndrome. J Clin Endocrinol Metab. 2006:91:48-53. doi:10.1210/jc.2005-1329.

9. Moran LJ, Ranasinha S, Zoungas S, Mcnaughton S, Brown W, Teede H. The contribution of diet, physical activity and sedentary behaviour to body mass index in women with and without polycystic ovary syndrome. Hum Reprod. 2013;28:2276-83. doi:10.1093/humrep/det256.

10. Huber-Buchholz MM, Carey DG, Norman RJ. Restoration of reproductive potential by lifestyle modification in obese polycystic ovary syndrome: role of insulin sensitivity and luteinizing hormone. J Clin Endocrinol Metab. 1999; 84:1470-4. doi:10.1210/jcem.84.4.5596. 
11. Crosignani PG, Colombo M, Vegetti W, Somigliana E, Gessati A, Ragni G. Overweight and obese anovulatory patients with polycystic ovaries: parallel improvements in anthropometric indices, ovarian physiology and fertility rate induced by diet. Hum Reprod. 2003;18:1928-32.

12. Legro RS, Dodson WC, Kunselman AR, et al. Benefit of Delayed Fertility Therapy with Preconception Weight Loss over Immediate Therapy in Obese Women with PCOS. J Clin Endocrinol Metab. 2016: jc20161659. doi:10.1210/jc.2016-1659.

13. Bhandari S, Ganguly I, Bhandari M, et al. Effect of sleeve gastrectomy bariatric surgery-induced weight loss on serum AMH levels in reproductive aged women. Gynecol Endocrinol. 2016: 1-4. DOl:10.3109/09513590.2016.1169267.

14. Ha L, Li X. Effect of high protein diet and regular exercise in obese patients with polycystic ovary syndrome. Ningxia Med. 2013;35:3.

15. Soares NP, Santos AC, Costa EC, et al. Diet-induced weight loss reduces DNA damage and cardiometabolic risk factors in overweight/obese women with polycystic ovary syndrome. Ann Nutr Metab. 2016;68:220-7. doi:10.1159/000444130.

16. He X, Tao Q, Li X. Influence of gender and age on the diagnostic criteria of overweight and obesity in adult with BMI. Chin J Public Health. 2009;25:4.

17. Rotterdam EA-SPcwg. Revised 2003 consensus on diagnostic criteria and long-term health risks related to polycystic ovary syndrome (PCOS). Hum Reprod. 2004;19:41-7.

18. Wijeyaratne CN, Seneviratne Rde A, Dahanayake S, et al. Phenotype and metabolic profile of South Asian women with polycystic ovary syndrome (PCOS): results of a large database from a specialist Endocrine Clinic. Hum Reprod. 2011;26:202-13. doi:10.1093/humrep/deq310.

19. Sam S. Adiposity and metabolic dysfunction in polycystic ovary syndrome. Horm Mol Biol Clin Investig. 2015;21:107-16. doi:10.1515/hmbci-2015-0008.

20. Pan B, Zhang X, Liu S. Evaluation of the ROC analysis in SPSS in the test/ diagnosis. Strait J Prev Med. 2003;9:5.

21. Chen L, Lan Z, Zhang D. The value of different obese criteria for the assessment of insulin resistance in women with polycystic ovary syndrome. Sichuan Da Xue Xue Bao Yi Xue Ban. 2013;44:5.

22. Zeng Q, He Y, Dong S, et al. Optimal cut-off values of BMl, waist circumference and waist:height ratio for defining obesity in Chinese adults. Br J Nutr. 2014:112:1735-44. doi:10.1017/S0007114514002657.

23. Oh JY, Sung YA, Lee HJ, Oh JY, Chung HW, Park H. Optimal waist circumference for prediction of metabolic syndrome in young Korean women with polycystic ovary syndrome. Obesity (Silver Spring). 2010;18: 593-7. doi:10.1038/oby.2009.297.

24. Costa EC, Sa JC, Soares EM, Lemos TM, Maranhao TM, Azevedo GD. Anthropometric indices of central obesity how discriminators of metabolic syndrome in Brazilian women with polycystic ovary syndrome. Gynecol Endocrinol. 2012:28:12-5. doi:10.3109/09513590.2011.583956.

25. Lavie CJ, Milani RV, Ventura HO. Obesity and cardiovascular disease: risk factor, paradox, and impact of weight loss. J Am Coll Cardiol. 2009:53: 1925-32. doi:10.1016/j.jacc.2008.12.068.

26. Lavie CJ, De Schutter A, Patel D, Artham SM, Milani RV. Body composition and coronary heart disease mortality-an obesity or a lean paradox? Mayo Clin Proc. 2011;86:857-64. doi:10.4065/mcp.2011.0092.

27. Lavie CJ, Milani RV, Ventura HO, Romero-Corral A. Body composition and heart failure prevalence and prognosis: getting to the fat of the matter in the "obesity paradox". Mayo Clin Proc. 2010:85:605-8. doi:10.4065/mcp.2010.0333.

28. Romero-Corral A, Montori VM, Somers VK, et al. Association of bodyweight with total mortality and with cardiovascular events in coronary artery disease: a systematic review of cohort studies. Lancet. 2006;368:666-78. doi:10.1016/S0140-6736(06)69251-9.

29. Zhu S, Wang Z, Heshka S, Heo M, Faith MS, Heymsfield SB. Waist circumference and obesity-associated risk factors among whites in the third National Health and Nutrition Examination Survey: clinical action thresholds. Am J Clin Nutr. 2002;76:743-9.

30. Wattanapenpaiboon N, Lukito W, Strauss BJ, Hsu-Hage BH, Wahlqvist ML, Stroud DB. Agreement of skinfold measurement and bioelectrical impedance analysis (BIA) methods with dual energy X-ray absorptiometry (DEXA) in estimating total body fat in Anglo-Celtic Australians. Int J Obes Relat Metab Disord. 1998:22:854-60.

31. Habib SS. Body mass index and body fat percentage in assessment of obesity prevalence in saudi adults. Biomed Environ Sci. 2013:26:94-9. doi:10.3967/0895-3988.2013.02.003.

32. Okorodudu DO, Jumean MF, Montori VM, et al. Diagnostic performance of body mass index to identify obesity as defined by body adiposity: a systematic review and meta-analysis. Int J Obes (Lond). 2010;34:791-9. doi:10.1038/ijo.2010.5

33. Carpenter CL, Yan E, Chen S, et al. Body fat and body-mass index among a multiethnic sample of college-age men and women. J Obes. 2013;2013: 790654. doi:10.1155/2013/790654

34. Madeira FB, Silva AA, Veloso HF, et al. Normal weight obesity is associated with metabolic syndrome and insulin resistance in young adults from a middle-income country. PLoS One. 2013;8:e60673. doi:10.1371/journal.pone. 0060673.

35. Lavie CJ, De Schutter A, Patel DA, Romero-Corral A, Artham SM, Milani RV. Body composition and survival in stable coronary heart disease: impact of lean mass index and body fat in the "obesity paradox". J Am Coll Cardiol. 2012;60:1374-80. doi:10.1016/j.jacc.2012.05.037.

36. Thibault R, Pichard C. The evaluation of body composition: a useful tool for clinical practice. Ann Nutr Metab. 2012;60:6-16. doi:10.1159/000334879.

37. Deurenberg-Yap M, Chew SK, Deurenberg P. Elevated body fat percentage and cardiovascular risks at low body mass index levels among Singaporean Chinese, Malays and Indians. Obes Rev. 2002;3:209-15.

38. Cruz P, Johnson BD, Karpinski SC, et al. Validity of weight loss to estimate improvement in body composition in individuals attending a wellness center. Obesity (Silver Spring). 2011;19:2274-9. doi:10.1038/oby.2011.102.

39. Wright CM, Sherriff A, Ward SC, McColl JH, Reilly JJ, Ness AR. Development of bioelectrical impedance-derived indices of fat and fat-free mass for assessment of nutritional status in childhood. Eur J Clin Nutr. 2008:62:210-7. doi:10.1038/sj.ejen.1602714

40. Bintvihok W, Chaikittisilpa S, Panyakamlerd K, Jaisamrarn U, Taechakraichana N. Cut-off value of body fat in association with metabolic syndrome in Thai peri- and postmenopausal women. Climacteric. 2013;16:393-7. doi:10.3109/ 13697137.2012.762762

41. Zabuliene L, Tutkuviene J. Body composition and polycystic ovary syndrome. Medicina (Kaunas). 2010;46:142-57.

42. Consultation WHOE. Appropriate body-mass index for Asian populations and its implications for policy and intervention strategies. Lancet. 2004:363: 157-63. doi:10.1016/S0140-6736(03)15268-3.

43. Alberti KG, Zimmet P, Shaw J. Metabolic syndrome-a new world-wide definition. A consensus statement from the International Diabetes Federation. Diabet Med. 2006:23:469-80. doi:10.1111/j.1464-5491.2006.01858.x.

\section{Submit your next manuscript to BioMed Central and we will help you at every step:}

- We accept pre-submission inquiries

- Our selector tool helps you to find the most relevant journal

- We provide round the clock customer support

- Convenient online submission

- Thorough peer review

- Inclusion in PubMed and all major indexing services

- Maximum visibility for your research

Submit your manuscript at www biomedcentral.com/submit
C BioMed Central 